\title{
ЧЕЛОВЕЧЕСКИЙ КАПИТАЛ В СИСТЕМЕ ФАКТОРОВ ОПЛАТЫ ТРУДА КВАЛИФИЦИРОВАННЫХ РАБОТНИКОВ
}

\author{
(c) 2018 Соболев Эдуард Неньевич \\ доктор экономических наук, ведущий научный сотрудник \\ Институт экономики Российской академии наук \\ 117218, г. Москва, Нахимовский пр., д. 32 \\ E-mail: edsobol@rambler.ru
}

В статье исследуется связь оплаты труда квалифицированных работников с их человеческим капиталом. Показано, что в России эта связь прослеживается слабо. Предлагается система мер по преодолению деформаций в оплате труда, базирующаяся на более полном учете профессионально-квалификационных и образовательных характеристик работников.

Ключевые слова: человеческий капитал, заработная плата, квалифицированный труд, отдача от образования, дифференциация оплаты труда.

Спецификой российской практики оплаты труда является слабый учет факторов, отражающих накопленный работниками человеческий капитал. Важнейшими из этих факторов - уровень профессионального образования и опыт работы по специальности, в ходе которой человеческий капитал обновляется и модернизируется. На практике при установлении размера вознаграждения за труд важность этих характеристик перекрывается неоправданно высокой ролью факторов, которые не зависят от работника, а отражают объективные параметры того или иного рабочего места. Это сфера экономической активности (процветающие или стагнирующие отрасли), территориальный фактор (крупный город, небольшой город, сельская местность, благополучный или дотационный регион), устойчивость экономического положения и финансовые результаты конкретного предприятия (фирмы), где занят тот или иной работник, уровень социальной ответственности и зарплатные стратегии менеджмента.

Положение усугубляется и тем, что вопросы оплаты квалифицированного труда на сегодняшний день практически выпали из сферы ответственности российского законодательства. В фокусе его внимания преимущественно размер минимальной зарплаты. Порой кажется, что помимо МРОТа и его соотношения с прожиточным минимумом (ПМ) никаких проблем в оплате труда нет. А с учетом того, что коллективно-договорное регулирование тоже ориентируется на минимальные уровни, у нас сложилась деформированная практика дифференциации.

Вопреки распространенному мнению, со-

гласно которому деформации в области оплаты квалифицированного труда имеют истоки в рыночных преобразованиях последнего десятилетия прошлого века, эти проблемы в значительной степени были заложены еще в предшествующий советский период, когда более полному учету квалификационных различий препятствовала общая линия на выравнивание трудовых доходов и недопущения бедности наименее квалифицированных слоев рабочей силы, получающих минимальную заработную плату. Это нашло отражение в сжатии тарифной сетки в позднесоветский период.

В результате уже к 70-м годам прошлого века был практически утрачен относительно высокий социальный статус и уровень материального благополучия широких слоев квалифицированных работников, занятых как в отраслях нематериального производства (образовании, здравоохранении), так и в промышленности, строительстве, на транспорте (инженерно-технические работники). Дело дошло до того, что ходе социологических опросов представители этих категорий сплошь и рядом сообщали завышенный размер собственной зарплаты, так как стыдились ее размеров.

Таким образом, на пороге рыночных преобразований в нашей стране хотя и отсутствовала весьма острая для многих регионов мира проблема высокой и растущей дифференциации трудовых доходов, но в то же время сложилось серьезное отставание в области оплаты квалифицированного труда от наиболее развитых экономик. На тот момент отрицательные экономические следствия этого отставания были в 
основном купированы «железным занавесом», который делал невозможными значительные масштабы оттока квалифицированного труда в страны, обеспечивающие адекватную квалификации работников отдачу на человеческий капитал [1]. Негативные социальные следствия со своей стороны смягчались бесплатным доступом к продукту отраслей нематериального производства и высоким уровнем социальной защищенности населения. Рыночные реформы, с одной стороны, открыли ворота неконтролируемой утечке умов, с другой,- резко ухудшили общие условия воспроизводства рабочей силы, что сильнее всего затронуло ее наиболее квалифицированные и образованные слои.

На рубеже тысячелетий существенная доля квалифицированных работников в самых разных сферах деятельности либо оказалась невостребованными на рынке труда, либо получали мизерное вознаграждение. По данным социологического опроса, проведенного в этот период Институтом экономики РАН, среди работников, получающих заработную плату в размере прожиточного минимума и ниже около 30\% имели высшее, а еще около 45\% среднее профессиональное образование [2].

В сферах нематериального производства, где сосредоточена значительная часть наиболее образованной рабочей силы, средняя заработная плата отставала от отраслей с низкой долей обладателей высшего образования. Особенно пострадали организации бюджетного сектора, где доля лиц с высшим и средним профессиональным образованием на начало 2000-х гг. колебалась в пределах 30-40\% в сравнении с 18-23\% в остальной экономике.

Противовесом этой тенденции выступило появление новых видов деятельности в растущих сегментах рыночной экономики. Развитие информационных технологий, финансовых и деловых услуг способствовали расширению спроса на соответствующие категории квалифицированной и хорошо оплачиваемой рабочей силы. Однако положение других обширных сегментов квалифицированных работников до сих пор продолжает оставаться весьма неблагоприятным.

Жесткая ограниченность бюджетных средств на оплату труда как следствие ущербной социальной политики неизбежно требовала и требует использования пресловутого советского опыта тарификации, когда повышение минимальной оплаты в условиях бюджетных ограничений зачастую приводило к «сжатию» тарифной сетки. Аналогичные процессы имеют место и в настоящее время с системой должностных окладов в науке и образовании. Тем самым внутри бюджетной сферы нарушаются материальные стимулы к труду более высокой квалификации, а далее - по цепочке - сдерживается оплата квалифицированных работников и в других секторах экономики. При этом «сжатие» распространяется не на всех работников бюджетной сферы. Другие принципы и ставки применяются для категорий государственных служащих, в результате чего средняя заработная плата в органах государственного управления почти в два раза выше, чем оплата работников в отраслях социальной инфраструктуры. Это также способствует усилению межфирменных различий в противовес квалификационным.

Что касается оценки тенденций в зарплатном неравенстве, то основной негатив кроется не в размерах дифференциации (в США такая же, если не большая дифференциация в заработках). Более важно, что в России эти разрывы зачастую слабо связаны с профессиональными характеристиками работников, с их человеческим капиталом.

В 1990-х и начале нулевых годов Институтом экономики РАН было проведено несколько раундов обследования социально-экономического положения работников по одному кругу предприятий, которое выявило две основные тенденции во внутрифирменной дифференциации оплаты труда. Первая - рост разрыва между оплатой труда руководителей предприятия (администрации) и основной массой работников. Одновременно существовала вторая устойчивая тенденция сближения заработков квалифицированных и менее квалифицированных работников [3].

С тех пор прошло немало времени, но положение - по большему счету - мало изменилось. Так, Обследование заработной платы по профессиям, проведенное Росстатом в октябре 2017 г. показало, что по величине оплаты труда вне конкуренции являются руководители, чьи заработки почти в два раза превышают средний уровень для всех обследованных работников. (Когда было первое обследование в 2005 г., превышение составляло 75\%, т.е. за 10 лет оно существенно возросло). Работники высшей квалификации получают всего лишь на 12\% выше 
средней оплаты. Что касается остальных групп работников, то все они, начиная от «специалистов средней квалификации» до «неквалифицированных работников» по зарплате недотягивали до средней [4].

В целом, исходя из результатов последнего обследования, можно сделать следующие выводы. По-прежнему сохраняется сильная статусная поляризация между руководителями и остальными категориями работников по оплате. В то же время отметим, что аналогичная ситуация имеет место и в других странах. В докладе MOT, специально посвященном проблеме неравенства в оплате труда, отмечалось, что в развитых странах около 80\% работников получают зарплату ниже средней по организации [5]. Для основной массы российских работников связь фактора квалификации и оплаты труда просматривается, но не является линейной. К примеру, труд синих воротничков ценится, по крайней мере, не ниже, чем белых, хотя квалификация у вторых выше. С чем это связано: со стиранием различий в сложности труда белых и синих воротничков, отсутствием средств на дифференциацию (например, компрессия заработков может быть следствием повышения MPOT в условиях жестких бюджетных ограничений) или наличием дисбалансов в спросе и предложении на рынке труда, вопрос требует специального изучения.

В России имеем также относительно слабую зависимость заработков от возраста и стажа, что также свидетельствует о деформациях в отечественном механизме формирования оплаты труда. Более опытные работники старших возрастов, обладающие несравненно более высокой квалификацией, получают всего лишь на 30-40\% больше, чем молодые и неопытные работники. Для сравнения: в США разница составляет 2,5 раза. Типичной является такая ситуация, когда заработная плата вновь пришедшего работника быстро растет в первое десятилетие его трудовой деятельности, а затем рост замедляется и она остается практически неизменной в течение последующих 20-25 лет. Кривые заработков по трудовому стажу ведут себя аналогично кривым по возрасту [6].

Определенные потери стал нести фактор образования - важнейшая составляющая квалификации работника. Если со второй половины 1990-х гг. наблюдался интенсивный рост отдачи от образования, которая достигла 8\% на каждый дополнительный год обучения в начале 2000-х гг., то в дальнейшем началось снижение отдачи. К концу нулевых годов она стала составлять около 7\% [7]. По прогнозам некоторых экспертов отдача от образования в России продолжит снижаться, несмотря на противоположную мировую тенденцию [8].

Причин здесь несколько. Прежде всего, конечно, сырьевая ориентация экономики, слабое развитие высокотехнологичных отраслей, что объективно ограничивает спрос на услуги высококвалифицированных работников. Снижение отдачи во многом результат и расцвета так называемого псевдообразования, когда многие вузы превратились из места получения знаний в предприятие по выдаче корочек. Отметим и рост доли образованных работников, занимающих рабочие места, не требующие столь высокого уровня квалификации, а также работа не по специальности. В результате дифференциация в заработках по уровням образования сглаживается и наблюдаемая отдача от человеческого капитала оказывается ниже, чем она могла бы быть, если бы работники распределялись по рабочим местам в соответствии с имеющейся у них профессиональной подготовкой. Есть оценки, что премия за более высокое образование была бы в таком случае как минимум в полтора раза выше [9].

Нельзя сказать, что в политике оплаты труда ничего не делается. В результате опережающего роста зарплаты укрепились позиции квалифицированных работников, занятых в ключевых отраслях нематериального производства - в образовании, здравоохранении, культуре. Это привело к позитивным изменениям соотношения заработной платы по видам экономической деятельности [10]. В то же время заработки специалистов социальных отраслей по-прежнему отстают от заработков специалистов в других отраслях экономики. К тому же наблюдается необоснованный рост интенсивности труда

В стране сложилась деформированная практика дифференциации, когда зарплата одновременно страдает как от «переизбытка» дифференциации, так и от ее недостатка. С одной стороны, имеет место один из самых высоких по мировым меркам отрывов зарплаты топ-менеджеров крупных компаний от рядовых работников, а с другой, невысокая дифференциация для подавляющей части работников. Поэтому актуальней ставить вопрос не столько о снижении дифференциации до некоего «социально-нор- 
мального» уровня, сколько о более полном учете в зарплате профессионально-квалификационных различий, человеческого капитала [11].

Что конкретно следует сделать по преодолению деформаций в оплате квалифицированного и высококвалифицированного труда?

Среди практических мер, которые лежат на поверхности, можно выделить следующие:

1. Создать минимумы оплаты по основным квалификационным группам и систему их практического внедрения. В последнее время возникла тенденция сведения всех проблем к МРОТ. Однако, не менее, если не более важна проблема оценки труда в зависимости от квалификации и сложности. В любом случае должен быть сохранен определенный порог чувствительности при переходе от разряда к разряду, от менее сложного к более сложному труду. Иными словами, в гарантиях минимума оплаты нуждается не только простой, но и сложный труд.

2. Восстановить значение нормирования труда, что позволит соединить высокие нормативные требования к трудовому вкладу и достойную заработную плату. Это столь непопулярная в наш век популизма тема связи оплаты труда с производительностью. Кроме того нормирование должно поставить жесткий предел росту интенсивности труда, чтобы это не отразилось на качестве работы. Это весьма актуально не только в традиционных сферах, которые обычно отождествляются с нормированием, но и в таких отраслях как образование и здравоохранение, где указы президента инициировали интенсификацию труда [12]. Ясно, здесь нужны серьезные исследования по проблеме редукции труда, поскольку мы еще не имеем полной формулы, на основе которой могли бы переводить сложный труд в простой. К сожалению, сегодня этим никто не занимается. Знаменитый НИИ труда разрушен и поменял свою тематику, из-за нехватки средств закрылся журнал «Человек и труд», практически не готовятся специалисты по нормированию в высшей школе. Не утратил своего значения прямой учет фактора образования и опыта при определении ставок оплаты труда в государственном секторе. Здесь главное - найти базу, от которой надо отталкиваться. Ориентирами могут служить соотношения, имеющиеся на рынке рабочей силы в странах с развитой экономикой или наиболее продвинутых развивающихся стран.

3. Повысить долю тарифа (оклада) в заработке. Как известно, фактор квалификации и образования более всего влияет именно на основную часть заработка. В России доля тарифа весьма незначительна (около 50\%), а в США свыше 95\%. Многочисленные доплаты ориентируют работника не на результат, а на мнение начальства.

4. Развивать институты нерыночного регулирования зарплаты, прежде всего механизмы социального партнерства, которые более-менее успешно функционирует во многих европейских странах. В России они формальны и неэффективны, но без них регулировать зарплату в коммерческом секторе невозможно[13].

5. Усилить роль региональных тарифных соглашений. Для зарплаты важно, чтобы возросла обязательность соблюдения соглашений на всех уровнях. Это реально и более всего возможно на уровне регионального тарифного соглашения. Межпрофессиональные и квалификационные соотношения в рамках этих соглашений можно сделать обязательными для всех предприятий (организаций) региона вне зависимости от того, заключили ли они такое соглашение или нет. Подобный опыт имеется в европейских странах, в частности во Франции.

6. Реформировать профсоюзы. Следует повсеместно переходить к организации профсоюзов не по производственно-отраслевому, а профессиональному принципу. Это позволит сформулировать единую позицию работников в рамках профессиональной группы на переговорах с работодателями по вопросам оплаты труда.

7. Необходима информационная прозрачность зарплат по профессиям на рынке труда. При определении зарплаты расчет должен делаться не на интуицию и слухи, а на сведения о заработках по конкретным профессиям в регулярно издаваемых бюллетенях.

Реализация этих мер, по сути, будет означать движение к более справедливой оценке квалифицированного труда и к более социально оправданной дифференциации в российской экономике.

\section{Библиографический список}

1. Марцинкевич В.И. Инвестиции в человека: экономическая наука и российская экономика // Мировая экономика и международные отношения. 2005. № 9. С. 29-39. 
2. Соболев Э.Н., Ломоносова С.В. Оплата труда в российской экономике: динамика, факторы, направления преобразований. Научный доклад. Москва. 2003.

3. Воейков М.И., Анисимова Г.В., Соболев Э.Н. Природа, факторы и социальные аспекты внутрикорпоративного неравенства в России // Вестник Российского гуманитарного научного фонда. 2012. № 3 (68). С. $43-51$.

4. Сведения о заработной плате работников организаций по категориям персонала и профессиональным группам работников за октябрь 2017 г. (статистический бюллетень). Москва. 2018. http://www.gks.ru/wps/ wcm/connect/rosstat_main/rosstat/ru/statistics/wages/labour costs/

5. Global Wage Report 2016/17: Wage inequality in the workplace - Geneva: ILO, 2016. P. XIX.

6. Заработная плата в России: эволюция и дифференциация / Под ред. В. Гимпельсона, Р. Капелюшникова. Москва. 2007. С. 414-422

7. Лукьянова А.Л. Отдача от образования: что показывает мета-анализ // Экономический журнал ВШЭ. 2010. № 3. C. 328-348.

8. Soboleva I. Paradoxes of the measurement of human capital // Problems of Economic Transition. 2010. V. 52 . № 11. P. 43-70

9. Капелюшников Р.И., Лукьянова А.Л. Трансформация человеческого капитала в российском обществе. Москва. 2010. С. 66-67.

10. Соболев Э.Н., Соболева И.В. Тенденции и факторы дифференциации заработной платы в российской экономике // Вестник Российского экономического университета им. Г.В. Плеханова. 2014. № 5 (71). С. 33-50.

11. Соболев Э.Н. Социальная политика в сфере труда: критерии эффективности и направления модернизации // Вестник Института экономики РАН. 2017. № 2. С. 32-46.

12. Ржаницына Л. С. Без стимулирования труда не поднять его производительность / Вестник Института экономики РАН. 2016. № 5. С. 56-69.

13. Российская социально-экономическая система: реалии и векторы развития / Отв. ред. Гринберг Р.С., Савченко П.В. Сер. Научная мысль (2-е изд. перераб. и доп.). Москва. 2016. С. 417-425.

Поступила в редакцию 10.10.2018 